\title{
СвК как основа ускорения разработки и производства гражданской электроники
}

Совместное заседание Секции № 9 МРГ при коллегии ВПК РФ и Координационного совета разработчиков и производителей РЭА и ЭКБ АО «Концерн ВКО «Алмаз-Антей»

Ю. Ковалевский

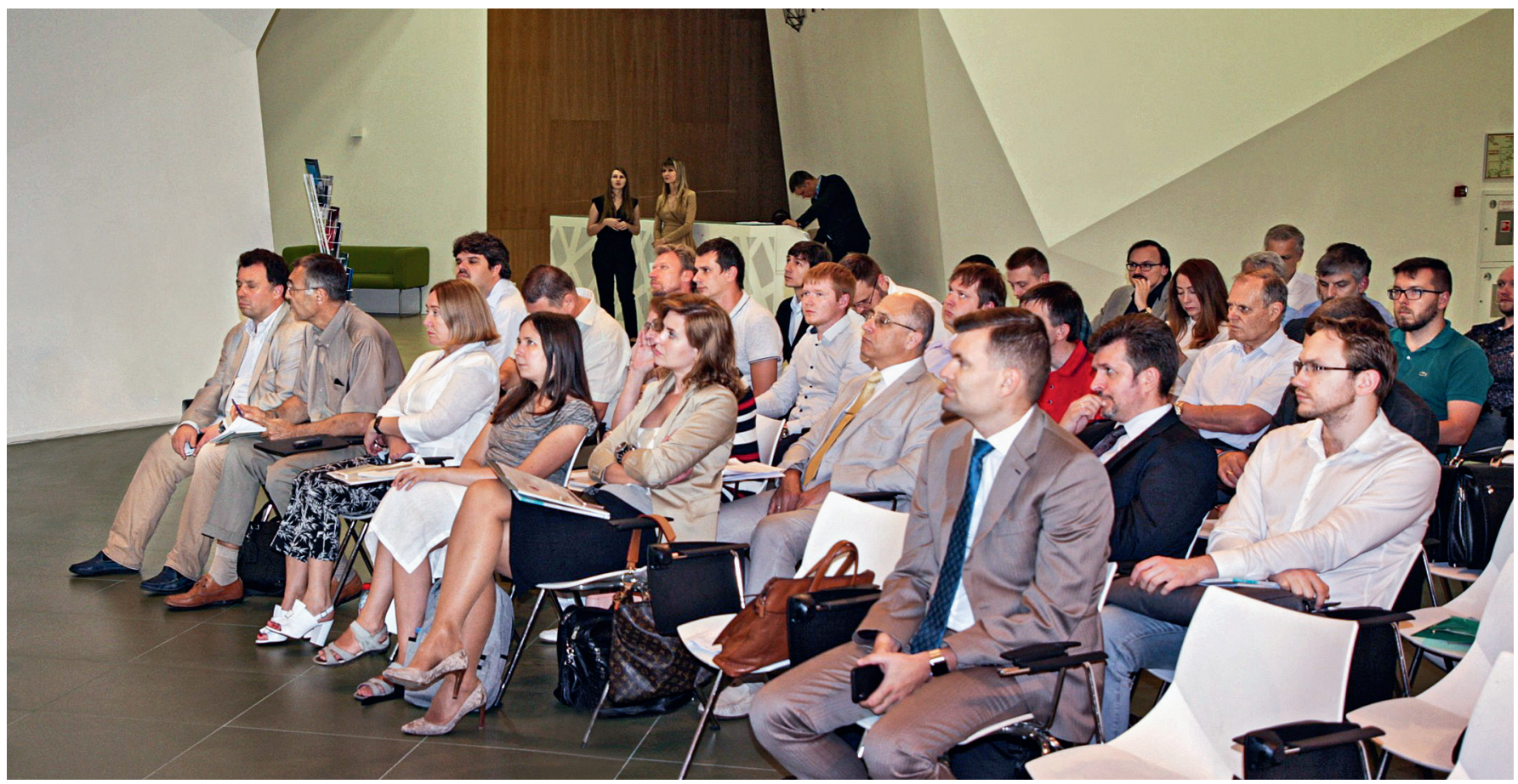

24 июня 2019 года на площадке ОЭ3 "Технополис "Москва" прошло совместное заседание Секции № 9 по участию малого и среднего бизнеса в разработке и производстве электронной компонентной базы (ЭКБ) Межведомственной рабочей группы (МРГ) при коллегии Военно-промышленной комиссии Российской Федерации (ВПК РФ) и Координационного совета разработчиков и производителей радиоэлектронной аппаратуры (РЭА) и электронной компонентной базы АО "Концерн ВКО "Алмаз-Антей". Темой мероприятия стало создание систем в корпусе (СвК) как основа ускорения разработки и производства продукции гражданского назначения.

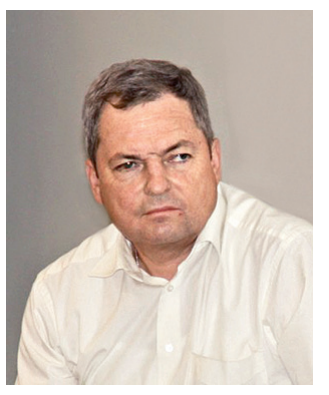

Мероприятие проводили председатель Координационного совета, начальник службы по развитию ЭКБ, ПКИ и материалов АО «Концерн ВКО «АлмазАнтей" К. А. Колегов и руководитель Секции № 9, директор АНО «Институт стратегий развития" П. А. Верник.
К. А. Колегов в своем докладе отметил большой потенциал малого и среднего бизнеса в участии в новых разработках Концерна ввиду высокой динамичности таких предприятий в создании инноваций, что играет важную роль при разработке передовых решений, в особенности с учетом специфики гражданского рынка. Докладчик призвал компании предлагать свои решения в области ЭКБ, комплектующих и материалов, которые могут стать основой для создания 
перспективных электронных изделий, при этом подчеркнув, что дочерние предприятия Концерна готовы рассматривать проекты, находящиеся на различных стадиях - от прототипа до изделия, готового к применению.

В отношении импортозамещения К. А. Колегов указал на то, что, в отличие от подхода, заключающегося в замене импортной ЭКБ, в Концерне приоритет отдается разработке новых решений на системном уровне, основанных на российской компонентной базе, призвав предприятия к участию и в этой работе.

Докладчик также привел ряд факторов, тормозящих развитие отечественной электронной техники, в частности указав на длительные сроки разработки ЭКБ, что вызвано в том числе бюрократическими процедурами. Также он подчеркнул важность сближения разработчиков аппаратуры и производителей ЭКБ, рассказав, какие меры предпринимаются в Концерне для того, чтобы разработки его дизайн-центров находились во взаимосвязи с имеющейся технологической базой.

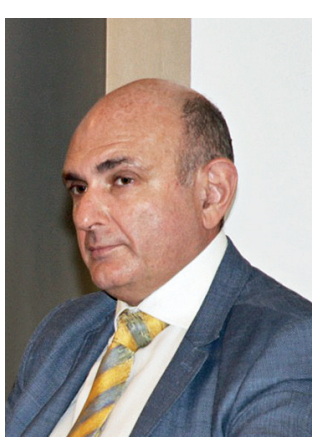

На важность взаимодействия между разработчиками ЭКБ и электронной аппаратуры указал в своем выступлении и П.А. Верник, поблагодарив представителей Концерна ВКО "Алмаз-Антей» за готовность к взаимодействию с предприятиями малого и среднего бизнеса в вопросах применения разработок ЭКБ в целях выполнения задач гражданской диверсификации и развития отечественной электроники гражданского назначения.

Переходя к теме мероприятия, П. А. Верник провел аналогию между принципами проектирования изделий на основе СвК и открытыми системами в других областях, включая вычислительную технику и телекоммуникации. По мнению докладчика, в современных условиях, характеризующихся ускорением развития и конкуренцией на глобальном уровне, открытые системы, обладающие высокой универсальностью и соответствующими экосистемами вокруг них, оказываются гораздо более живучими, чем закрытые системы. Этот эффект будет усиливаться в дальнейшем по мере развития таких концепций, как "Индустрия 4.0» и цифровизация производств, что будет приводить к созданию практически уникальных изделий под каждого заказчика на массовом рынке. В этих условиях большую роль может сыграть модульный принцип конструирования, и СвК в этом отношении обладают высоким потенциалом.
Кроме того, благодаря модульному принципу, СвК позволяют существенно сократить сроки разработки новой ЭКБ и снизить Количество итераций при создании нового изделия в сравнении с разработкой систем на кристалле, при которой требуется проектирование нового кристалла с отработкой прототипа даже при внесении относительно небольших изменений. Это особенно важно для того, чтобы в кратчайшие сроки достичь технологического лидерства по наиболее важным направлениям гражданского рынка, в которых узким местом остается отечественная ЭКБ современного уровня, что во многом связано с тем, что из-за динамичности этого рынка разработки, выполняемые по классической схеме, успевают устареть еще до их готовности к применению.

Также П.А. Верник рассказал о площадке, на которой проходило мероприятие, охарактеризовав ОЭ3 "Технополис "Москва" как уникальный научнопроизводственный объект, на котором реализована вся необходимая инфраструктура для высокотехнологичных и инновационных компаний, включающая в том числе частично подготовленные чистые помещения. Эта структура создана правительством Москвы и оказывает активную помощь расположенным на ее территории предприятиям, в том числе работающим в области создания передовой ЭКБ

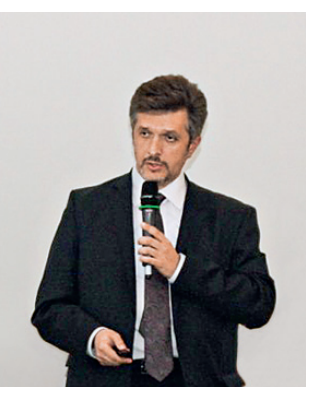

Д. В. Холодняк,

профессор кафедры микрорадиоэлектроники и технологии радиоаппаратуры спбгЭту "лЭТИ", посвятил свой доклад СВЧ-устройствам и многофункциональным модулям на основе низкотемпературной совместно обжигаемой керамики (LTCC). Рассказав о возможностях и преимуществах технологии LTCC для создания СВЧ-компонентов и модулей, докладчик привел примеры областей ее применения и разработок на ее основе, как зарубежных, так и российских, включая разработки университета. Было отмечено, что данная технология открывает большие возможности с точки зрения интеграции, позволяя создавать СВчСвК, объединяющие в одном модуле различные составляющие, в том числе МИС и др., размещать пассивные компоненты обвязки внутри многослойных коммутационных структур LTCC, выполнять сверхузкие линии передачи. При этом диапазон рабочих частот может достигать очень высоких значений. В частности, существуют примеры зарубежных разработок с частотами до 122 и даже 150 ГГц, что не только удовлетворяет потребностям таких высокочастотных областей 
применения, как автомобильные радары и связь 5G миллиметрового диапазона, но с запасом превышает их требования.

В миллиметровом и суб-терагерцовом диапазонах практический интерес представляет возможность создания в LTCC-структурах интегрированных в подложку волноводов, две параллельные стенки которых выполняются в виде проводящих слоев, а две другие - в виде соединяющих их рядов переходных металлизированных отверстий. Линий передачи такой конструкции сочетают в себе преимущества планарных линий передачи, такие как малые габариты и вес и простота изготовления, с малыми вносимыми потерями, присущими традиционным металлическим волноводам.

Кроме того, было отмечено, что технология LTCC позволяет встраивать в модуль оптоволоконные каналы, а также каналы для жидкостного охлаждения. Помимо отвода тепла, применение решений из области микрофлюидики создает возможность использования СвК на основе LTCC в таких сферах, как биология и медицина.

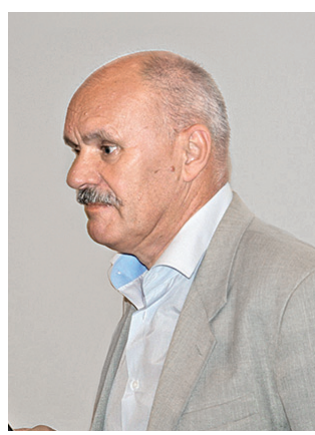

С. П.Тимошенков, директор Института нано- и микросистемной техники нИу МИэт, сосредоточил свой доклад на датчиках и измерительныхсистемах на основе МЭМС. Докладчик отметил, что, хотя существует теоретическая возможность интеграции нескольких МЭМС, схемы обработки сигналов, процессора и т.п. на одном кристалле, на практике это сделать, как правило, не удается, и оказывается необходимым применение различных вариантов 3D-интеграции. В этом отношении очень перспективной оказывается технология LTCC, которая открывает возможности создания многоосевых и мультисенсорных СвК

С. П. Тимошенков рассказал, что в университете была освоена технология переходных отверстий в кремнии (TSV), которая позволяет очень компактно упаковывать несколько кристаллов, однако это решение требует корпусирования, и в этом случае LTCC также может представлять интерес.

Докладчик сообщил и о других технологиях, освоенных в МИЭТ, в частности о технологии прямого лазерного формирования коммутационных элементов, внутреннего монтажа со встраиванием кристаллов в подложки из различных материалов, а также межуровневой коммутации с помощью торцевой металлизации.

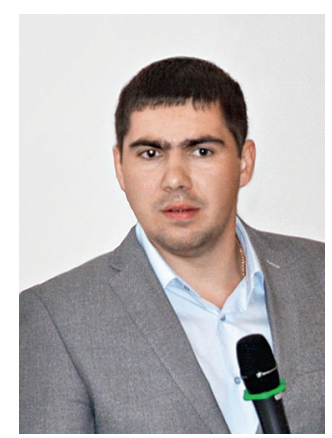

А.С. Петушков, начальник отдела микроэлектроники и полупроводниковой техники ФГУП "МНИИРИП", в своем докладе еще раз обратил внимание на основные тенденции в современной электронике, связанные с построением цифровой экономики, развитием технологий 5С и т.д., подчеркнув, что в условиях повышения требований к функциональным возможностям изделий и уменьшения топологических норм, которые рано или поздно приведут к достижению физических пределов традиционных микроэлектронных технологий, растет спрос на СвК как на концепцию, потенциально способную совершить в скором будущем технологический скачок.

Докладчик упомянул ряд проектов целевых программ, предполагающих развитие во всей цепочке создания отечественной электроники от материалов до конечных изделий, в чем также могут сыграть роль СвК. При этом было отмечено, что для разработки СвК в первую очередь необходимо создание сборочных технологий. Также немаловажным фактором является устранение информационного вакуума, на что, в частности, направлено создание на базе ФГУП "МНИИРИП» торгово-информационной площадки «ЭКБ МАРКЕТ».

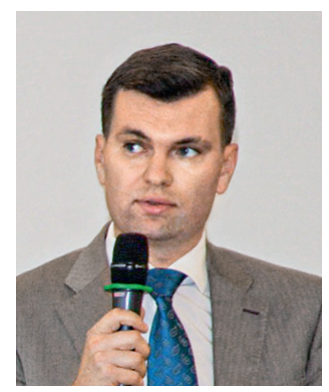

Заместитель генерального директора ФГБУ "Фонд содействия развитию малых форм предприятий в научно-технической сфере" А. В. Микитась привел сведения о фонде, подчеркнув, что эта организация направлена на поддержку именно малых инновационных компаний на всех этапах проектов - от идеи до вывода на стадию продаж. Докладчик также рассказал о том, что ранее фонд занимался поддержкой в разных сферах; сейчас же существуют планы по концентрации поддержки на отдельных отраслях, одной из которых может стать разработка ЭКБ. В этом направлении подготовлен концепт программ, основанных на действующих инструментах фонда, которые могут быть адаптированы для поддержки создания ЭКБ гражданского назначения. Докладчик призвал участников мероприятия ознакомиться с данным концептом и представить свои замечания и предложения по этому вопросу. 


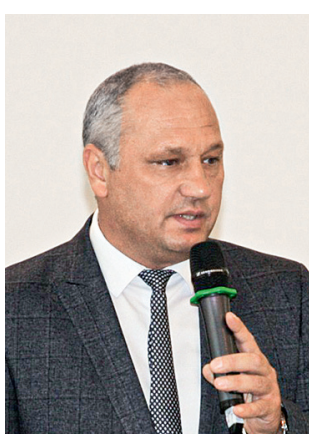

В. А. Косевской, директор по производству АО «НПЦ СпецЭлектронСистемы" (НПц сэс), представил доклад, посвященный конструированию и технологии изготовления СвК на базе LTCC. Докладчик рассказал о том, что в основу недавно созданного производства НПЦ СэС были заложены наиболее актуальные принципы, такие как миниатюризация изделий, повышение интеграции, сокращение сроков от идеи до готового к эксплуатации изделия. Одним из основных видов продукции, изготавливаемых на производстве, являются многослойные керамические структуры на LTCC. Конструкции, создаваемые на основе данных структур, могут объединять в себе три функции - конструктивную, коммутационную и, собственно, электронные элементы.

Производство укомплектовано оборудованием, позволяющим не только получать LTCC-структуры, но и изготавливать на их основе законченные СвК, а также проводить оперативные измерения и испытания, что решает задачу сокращения сроков создания готовых изделий. Уменьшению данных сроков также способствует возможность обоснованного сокращения количества необходимых испытаний образцов новых изделий.

В. А. Косевской привел основные достоинства СвК на основе LTCC-структур. При этом он отметил, что для эффективного создания таких СвК необходимо изменить идеологический подход к разработке и перейти от "плоского" представления к работе в объеме, что позволит в полной мере воспользоваться преимуществами этой технологии.

Также в докладе были приведены примеры уже выполненных разработок и направлений исследований, проводимых на предприятии в настоящее время.

В рамках мероприятия была организована экскурсия на производственную площадку НПЦ СЭС на территории ОЭЗ «Технополис «Москва».

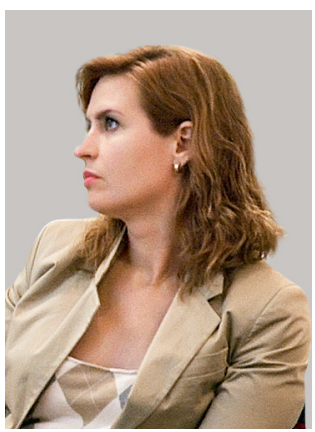

С кратким докладом на мероприятии выступила Е.А. Полищук, старший менеджер по работе с клиентами AO «Российский экспортный центр", рассказав о продуктовой линейке, предлагаемой центром для содействия выводу продукции российских предприятий на мировой рынок, включающей консультационные услуги по таким вопросам, как сертификация, патентование, логистика, а также субсидирование до 80\% затрат на участие в международных выставках и другие услуги по финансовой поддержке компаний. Кроме того, центр оказывает содействие в работе со сложными рынками, например рынками некоторых африканских стран, в отношении страховки рисков. Е. А. Полищук отметила, что центр будет рад помочь в экспортной деятельности компаниям электронной промышленности, при этом от самих компаний необходима помощь в определении целевой области ввиду специфики данного вида продукции.

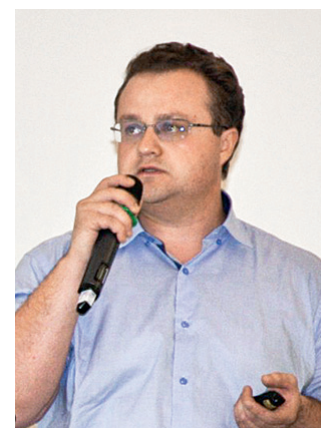

В.А. Бутузов, руководитель отдела разработки ООО «ОКБ Пятое Поколение", в своем докладе привел общие сведения о компании и рассказал о ее взаимодействии с другими предприятиями, в том числе расположенными в Технополисе "Москва". Докладчик остановился на одной из разработок компании - цифровом изоляторе, созданном совместно с НПЦ СЭС и Крокус Наноэлектроника. Этот микромодуль на основе LTCC, испытательный образец которого был получен в очень короткие сроки практически после первой итерации, по словам докладчика, представляет собой задел, который позволит создать целое семейство модулей развязки высокоскоростных интерфейсов, решений с гальванической развязкой питания и др. Также подобные устройства могут встраиваться в СвК в качестве бескорпусных элементов для получения более сложных систем с гальванической развязкой. Данную работу В. А. Бутузов охарактеризовал как пример удачного сотрудничества компаний, находящихся на территории Технополиса «Москва».

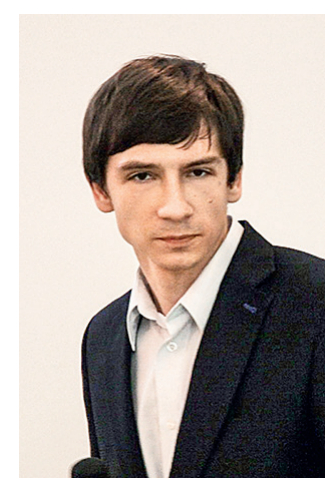

Начальник отдела разработки универсальных электронных модулей АО "ПКК Миландр" Д. Ю. Шедяков представил вниманию присутствующих ряд разработанных АО «ПКК Миландр" микросборок и микромодулей источников питания, выполненных в виде изделий в металлокерамических корпусах из высокотемпературной керамики, в том числе с использованием технологии flip-chip. Также были представлены отладочные комплекты и комплексы отладки для них. 


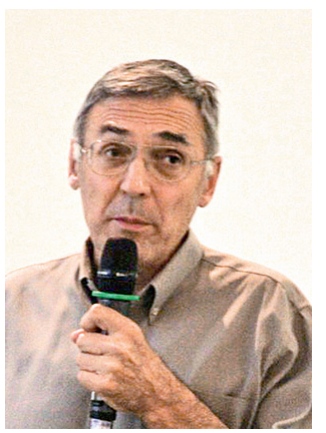

Помимо конструирования и изготовления коммутационных оснований и корпусов, а также сборочных технологий, для создания СвК необходимо обеспечение разработок бескорпусными кристаллами. Этому вопросу применительно к СВЧ-электронике был посвящен доклад генерального директора АО "Светлана-Рост" В.П.Чалого, который рассказал о возможностях кристального производства компании по технологиям GaAs с проектными нормами 0,5 и 0,25 мкм. Докладчик сообщил, что по первой технологии уже выполнено порядка 150 проектов, по второй - около 25 проектов. По оценке В. П. Чалого, разработка типового проекта с использованием PDK, предоставляемого AO «Светлана-Рост», занимает от 1 до 3 мес., срок изготовления кристалла составляет от 2,5 до 4 мес.

В качестве итога доклада прозвучало то, что в России уже есть все составляющие для движения вперед: дизайн-центры, фаундри, изготовление корпусов и сборочные технологии. Объединив усилия, уже можно получить результат, при условии что потребители четко сформулируют свои потребности в ЭКБ

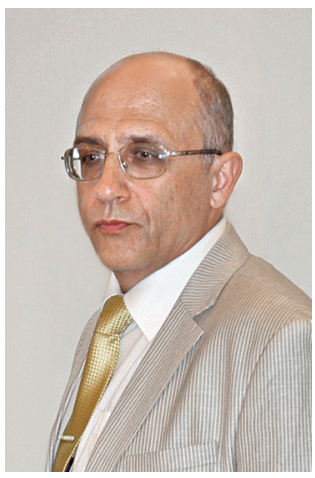

О.В.Машинин, генеральный директор ООО "БУТИС", также затронул в своем докладе вопрос взаимодействия между предприятиями. По его словам, компания "БУТИС", основной продукцией которой являются различные компоненты на поверхностных акустических волнах, в том числе фильтры на ПАВ для поверхностного монтажа, предназначенные для систем ГлОНАСС и GPS, успешно сотрудничает с ООО "Маппер"компанией, расположенной в Технополисе "Москва", а совместно с НПЦ СЭС начинает разработку модулей на основе LTCC в форме CвK. В докладе были приведены некоторые новые разработки компании, а также представлено сравнение некоторых серийных модулей с их аналогами - модулями на основе LTCC, показывающее преимущество последних с точки зрения основных параметров назначения и массогабаритных характеристик.

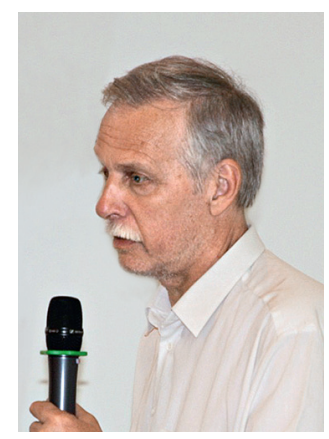

Со стороны заказчика ЭКБ выступил представитель одного из предприятий, входящих в состав Концерна ВКО “Алмаз-Антей", Б.Б.Батуров, рассказав о состоянии в сфере отечественной Рч-и СВЧЭКБ и текущих потребностях в этой области. Докладчик присоединился К мнению о том, что в настоящее время очень остро стоит вопрос о сокращении сроков разработки и поставки ЭКБ российского производства, а также отметил необходимость уделения внимания созданию отечественных материалов, в особенности высокочастотных

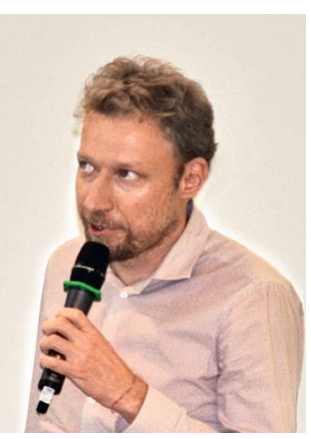

Последний доклад мероприятия был представлен С. Ю.Даценко, начальником отдела АО «НПп "Цифровые решения", рассказавшим о некоторых изделиях компании. Докладчик сделал особый акцент на перспективных разработках в области твердотельных накопителей данных на основе NAND флеш-памяти в различных форм-факторах, включая СвК, указав на важность создания отечественных накопителей как одного из необходимых компонентов цифровых систем.

В завершение заседания П. А. Верник еще раз поблагодарил всех участников мероприятия и отдельно представителей Концерна ВКО "АлмазАнтей", добавив, что данным общением создается прецедент выстраивания взаимодействия между производителями РЭА и малыми предприятиями - разработчиками ЭКБ, служащего эффективному развитию отечественной электроники и гражданской диверсификации, и выразив надежду, что к такому диалогу подключатся другие предприятия и концерны радиоэлектронной промышленности.

К. А. Колегов также выразил благодарность присутствующим за проявленный интерес к совместной работе и отметил важность подобных мероприятий для установления контактов между производителями и потребителями ЭКБ. Также он охарактеризовал площадку Технополиса "Москва» как перспективную для проведения подобных встреч. 


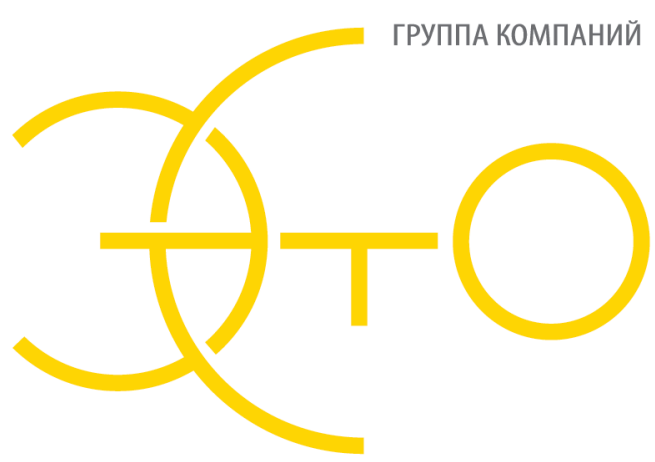

ЭЛЕКТРОННОЕ СПЕЦИАЛЬНОЕ ТЕХНОЛОГИЧЕСКОЕ ОБОРУДОВАНИЕ
Акционерное общество

«Научно-производственное предприятие

«Электронное специальное

технологическое оборудование»
124460, г. Москва, Зеленоград, Георгиевский проспект, д.5, стр.1 тел.: (499) 729-7751, факс: (499) 479-1239 info@nppesto.ru www.nppesto.ru

«GROOVY ICP» - технология будущего: система критического травления диэлектриков для массовых производств на основе уникального узкозазорного плазмохимического реактора

Разработка A0 «НПП «ЭСТО» при финансовой поддержке Министерства промышленности и торговли Российской Федерации

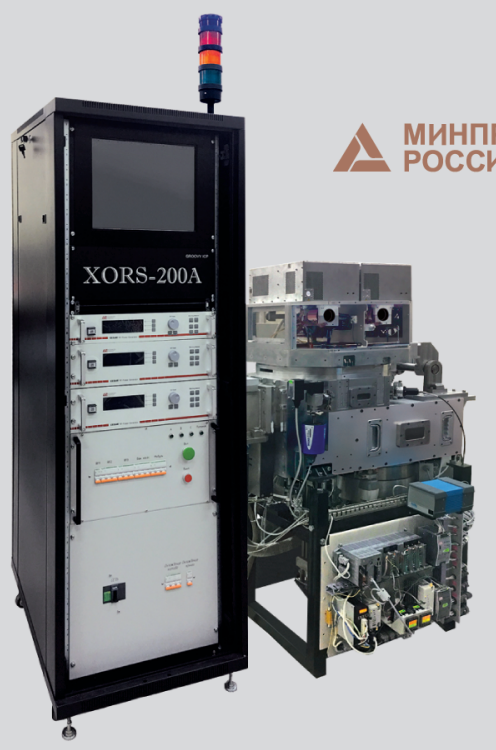

Группа компаний ЭСТО более 20 лет производит оборудование для микроэлектроники в собственном инженерно-производственном комплексе метражом в 5000 кв.м в г. Зеленограде

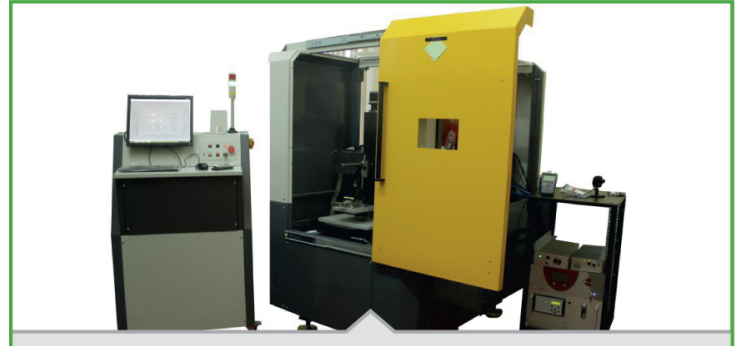

Оборудование для лазерной микрообработки: резка, фрезерование, скрайбирование, прошивка отверстий

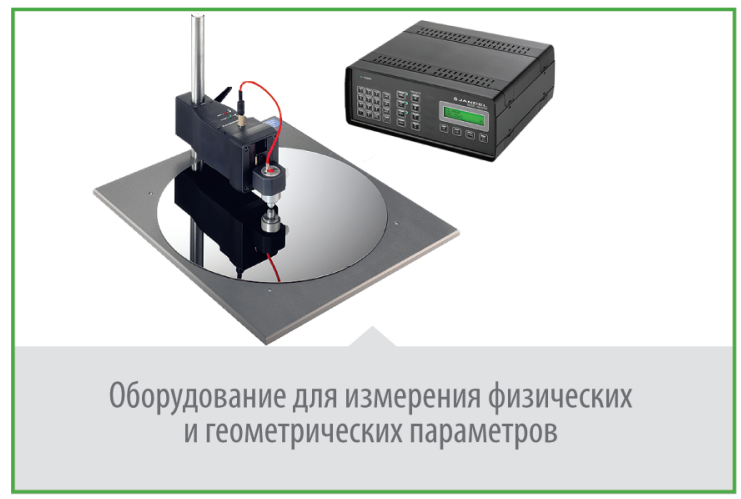

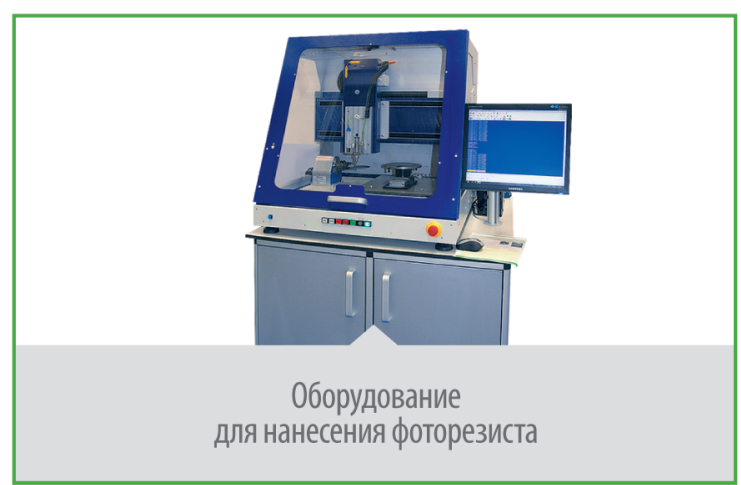

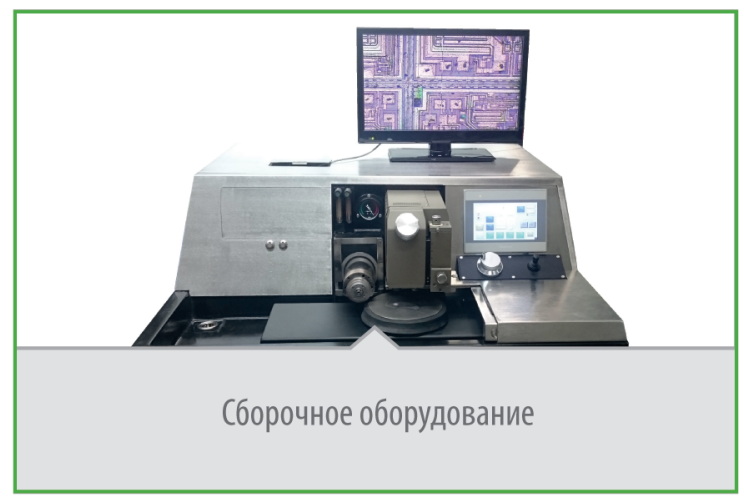

